\title{
Insulin is secreted upon glucose stimulation by both gastrointestinal enteroendocrine K-cells and L-cells engineered with the preproinsulin gene
}

\author{
${ }^{1,3}$ Gonzalo Encina, ${ }^{2}$ Fernando Ezquer, ${ }^{2}$ Paulette Conget, $1,3,4$ Yedy Israel \\ ${ }^{1}$ Laboratory of Gene Therapy, Department of Pharmacological and Toxicological Chemistry, Universidad de Chile, Santiago, Chile. \\ ${ }^{2}$ Instituto de Ciencias, Facultad de Medicina Clínica Alemana Universidad del Desarrollo, Santiago, Chile. \\ ${ }^{3}$ Millennium Institute for Cell Dynamics and Biotechnology, Santiago, Chile, and \\ ${ }^{4}$ Department of Pathology, Anatomy and Cell Biology, Thomas Jefferson University, Philadelphia PA.
}

\begin{abstract}
Transgenic mice carrying the human insulin gene driven by the K-cell glucose-dependent insulinotropic peptide (GIP) promoter secrete insulin and display normal glucose tolerance tests after their pancreatic $\beta$-cells have been destroyed. Establishing the existence of other types of cells that can process and secrete transgenic insulin would help the development of new gene therapy strategies to treat patients with diabetes mellitus. It is noted that in addition to GIP secreting K-cells, the glucagon-like peptide 1 (GLP-1) generating L-cells share/ many similarities to pancreatic $\beta$-cells, including the peptidases required for proinsulin processing, hormone storage and a glucosestimulated hormone secretion mechanism.

In the present study, we demonstrate that not only K-cells, but also L-cells engineered with the human preproinsulin gene are able to synthesize, store and, upon glucose stimulation, release mature insulin. When the mouse enteroendocrine STC-1 cell line was transfected with the human preproinsulin gene, driven either by the K-cell specific GIP promoter or by the constitutive cytomegalovirus (CMV) promoter, human insulin co-localizes in vesicles that contain GIP (GIP or CMV promoter) or GLP-1 (CMV promoter). Exposure to glucose of engineered STC-1 cells led to a marked insulin secretion, which was 7-fold greater when the insulin gene was driven by the CMV promoter (expressed both in K-cells and L-cells) than when it was driven by the GIP promoter (expressed only in K-cells).

Thus, besides pancreatic $\beta$-cells, both gastrointestinal enteroendocrine K-cells and L-cells can be selected as the target cell in a gene therapy strategy to treat patients with type 1 diabetes mellitus.
\end{abstract}

Key terms: Type 1 diabetes mellitus, preproinsulin gene, gastrointestinal enteroendocrine cells, K-cells, L-cells.

\section{INTRODUCTION}

While in early studies the regulation of blood glucose was considered to be controlled mainly by the endocrine pancreas, it is now clear that cells in the gastrointestinal tract can sense carbohydrates and other food components, releasing hormones that potentiate the glucose-dependent liberation of insulin by pancreatic $\beta$-cells (McIntyre et al., 1964, Perley \& Kipnis, 1970, Dupré et al., 1973). Gastrointestinal enteroendocrine K-cells and L-cells release the glucose-dependent insulinotropic peptide (GIP) and glucagon-like peptide 1 (GLP-1), respectively.

Due to their common developmental origin, pancreatic $\beta$-cells, K-cells and L-cells show marked similarities, which include: (i) the expression of the $\mathrm{PC} 1 / 3$ and $\mathrm{PC} 2$ peptidases needed for the conversion of proinsulin to insulin, (ii) the presence of GLUT-2 glucose transporter, (iii) a glucosedependent mechanism for hormone secretion, with granules that can store and readily secrete their respective hormones (Spooner et al., 1970, Baggio \& Drucker 2007). Nonetheless, gastrointestinal enteroendocrine cells are not susceptible to the autoimmune-mediated destruction of pancreatic $\beta$-cells observed in patients with type 1 diabetes mellitus (Vilsbøll et al., 2003).

Interestingly, in healthy individuals, plasma GIP and GLP-1 levels kinetically match the changes in plasma insulin levels following meals (Fujita et al., 2004). Thus, it is expected that if gastrointestinal enteroendocrine cells of patients with type 1 diabetes mellitus were endowed with the ability to express the preproinsulin gene, they could contribute to the normalization of postprandrial blood glucose. A proof-of-principle of this hypothesis was the data generated in transgenic mice carrying the human insulin gene under the K-cell specific GIP promoter (Cheung et al., 2000). When rendered diabetic by streptozotozin-mediated destruction of their pancreatic $\beta$-cells, these animals showed normal glucose tolerance tests results and expressed human insulin in cells in the stomach and duodenum. While this study shows that K-cells might be a good target for therapeutic strategies, embryonic transgenesis cannot be applied to treat patients. It is also noted that these authors did not address the possibility that cells other than $\mathrm{K}$-cells might also have the ability to secrete transgenic insulin upon glucose stimulation.

Several studies have reported gene-based strategies targeting different organs and tissues designed for the treatment of individuals with type 1 diabetes mellitus (Kolodka et al., 1995, Lipes et al., 1996, Goldfine et al., 1997, Bartlett et al., 1997, Bochan et al., 1999, Falqui et al., 1999, Olson et al., 2003). However, to date a timed glucosedependent release of preformed insulin is an unachieved goal. Gatrointestinal enteroendocrine cells might constitute ideal gene therapy cell targets to manage postprandial glycemia levels.

\footnotetext{
* Reprint requests to: Gonzalo Encina, Ph.D., Laboratory of Gene Therapy, University of Chile, Sergio Livingstone (Ex Olivos) 1007, Independencia, Santiago, RM 11111, Chile. Email: gencina@med.uchile.cl - Telephone: (56 2) 9782943 - Fax: (56 2) 7377291
} 
The aim of our work was to assess in vitro if the transfection into K-cells and L-cells of the human preproinsulin gene, driven either by the GIP promoter or by cytomegalovirus (CMV) promoter, results in mature insulin (i) synthesis, (ii) storage in granules, and (iii) secretion upon glucose stimulation. We also compared the relative contribution of a K-cell specific promoter versus a constitutive promoter.

\section{MATERIALS AND METHODS}

\section{Cell line and culture conditions}

The murine plurihormonal mixed intestinal STC-1 cell line (Rindi et al., 1990) was obtained from the ATCC with permission of Dr. D. Hanahan (University of California, San Francisco). Cells were cultured in DMEM (Invitrogen, Auckland, New Zealand) containing 10\% fetal bovine serum (FBS; Hyclone, Logan, UT, USA) supplemented with 100 $\mathrm{IU} / \mathrm{mL}$ penicillin (Invitrogen) and $50 \mu \mathrm{mol} / \mathrm{L}$ streptomycin (Invitrogen), in an atmosphere of 5\% CO2 and 100\% humidity.

Plasmids

pAAV-CMV/eGFP was obtained from Stratagene (Cedar Creek, TX, USA). To construct pAAV-GIP/eGFP, the 1,227 bp rat GIP promoter (nucleotides -1153 to +7 ) was amplified from genomic DNA by PCR, cloned into pGEM-T Easy (Promega, Madison, WI, USA) and sequenced to confirm that no errors were introduced into the product. The upstream and downstream primers used were $\left(5^{\prime}\right)$ - ATC TCT CCA GTC CCT TCC TC $-\left(3^{\prime}\right)$ and (5')- GGA TCC AGC TCT TCC AGG AGG GCA GGA TG - (3'), respectively. The fragment containing the GIP promoter was excised from pGEM-T Easy with the use of Not I (Promega) restriction enzyme and ligated into Not I site of the pAAV-MCS (Stratagene) using T4 DNA ligase (Promega). To construct pAAV-CMV/INS, the complete human preproinsulin gene (nucleotides +9 to +1831 ) was amplified from genomic DNA by PCR, cloned into pGEM-T Easy (Promega) and sequenced to confirm that no errors were introduced into the product. The upstream and downstream primers used were (5')- GGA TCC AGG ACA GGC TGC ATC $-\left(3^{\prime}\right)$ and $\left(5^{\prime}\right)$ - CCT CCA CAG GGA CTC CAT CAG - $\left(3^{\prime}\right)$, respectively. The fragment containing the human preproinsulin gene was excised from pGEM-T Easy using EcoR I restriction enzyme (Promega) and subsequently cloned into the EcoR I restriction site of the PAAV-MCS.

To construct pAAV-GIP/INS, a BamH I site was included at the $5^{\prime}$ end of the downstream primer for the GIP promoter and the upstream primer for the preproinsulin gene. Fragments containing the GIP promoter and the human preproinsulin were excised from pGEM-T Easy using Not I (Promega) and BamH I (Invitrogen, Carlsbad, CA, USA) restriction enzymes. A three-fragment ligation was performed using T4 DNA ligase (Promega) to insert the rat GIP promoter and the human preproinsulin gene into Not I site of the pAAV-MCS (Stratagene).

Assessment of transfection efficiency and promoter strength: STC-1 cells seeded in 6-well plates and grown to $60 \%$ confluence were transfected with $2 \mu \mathrm{g}$ of $\mathrm{pAAV}-\mathrm{GIP} / \mathrm{eGFP}$ or pAAV-CMV/eGFP plasmids using Lipofectamine 2000 (Invitrogen, Carlsbad, CA, USA) in serum free DMEM. After six hours, FBS was restored. Two days later, the cells were trypsinized (Invitrogen) and centrifuged at $500 \times \mathrm{g}$ for 10 minutes at room temperature. The pellet was resuspended and cells were fixed with $2 \%$ p-formaldehyde (Sigma-Aldrich St. Louis, MO, USA) in PBS. Finally, eGFP fluorescence was measured in cells using a BD FACSCanto ${ }^{\mathrm{TM}}$ flow cytometer, and data obtained were analyzed with the Weasel 2.5 Software.

Co-localization of human insulin with mouse GIP or mouse GLP-1

STC- 1 cells seeded on sterile $18 \times 18 \mathrm{~mm}$ cover slips and grown to $60 \%$ confluence were transfected with $2 \mu \mathrm{g}$ of pAAV-GIP/ INS or pAAV-CMV / INS using Lipofectamine 2000 (Invitrogen) in serum free DMEM. After six hours, FBS was restored. Two days later, cover slips were gently washed twice with PBS. Subsequently, cells were fixed with $4 \%$ p-formaldehyde (Sigma-Aldrich) in $100 \mathrm{mM}$ PIPES buffer, $\mathrm{pH}$ 6.8, containing $0.04 \mathrm{M} \mathrm{KOH}, 2 \mathrm{mM}$ EGTA, and $2 \mathrm{mM} \mathrm{MgCl}$ for 20 minutes and washed three times with $50 \mathrm{mM}$ Tris- $\mathrm{HCl}$ buffer, $\mathrm{pH}$ 7.6, containing $0.15 \mathrm{~N} \mathrm{NaCl}$ and $0.1 \%$ sodium azide (universal buffer). Cells were permeabilized with $0.1 \%$ Triton X-100 (Sigma-Aldrich) in universal buffer for 10 minutes, washed twice with universal buffer, and then blocked with $2 \%$ bovine serum albumin in the same buffer for 30 minutes. Cells were then incubated simultaneously with mouse monoclonal IgG anti-human mature insulin (2D11-5, 1:100), and goat polyclonal IgG anti-mouse GIP (Y-20, 1:100) or goat polyclonal IgG antimouse GLP-1 (C-17, 1:100) (all from Santa Cruz Biotechnology, Santa Cruz, CA, USA), at room temperature for one hour. After washing, cells were incubated simultaneously with FITCconjugated anti-mouse IgG (1:200) and TR-conjugated anti-goat IgG (1:200) (all from Santa Cruz Biotechnology). Samples were then mounted onto slides with UltraCruz ${ }^{\mathrm{TM}}$ Mounting Medium (Santa Cruz Biotechnology) and optical sections were obtained following excitation at 488 or $543 \mathrm{~nm}$ with a Carl Zeiss LSM 410-Axiovert 100 confocal microscope.

Human mature insulin secretion assay in standard culture condition with glucose stimulation

STC- 1 cells plated at $10^{5}$ cells/well on 12-well plates and grown to $60 \%$ confluence were transfected with $2 \mu \mathrm{g}$ of pAAVGIP/INS or pAAV-CMV/INS using Lipofectamine 2000 (Invitrogen) in serum free DMEM. After six hours, FBS was restored. When cells were $80 \%$ confluent, culture medium was replaced either by DMEM or Krebs-Ringer bicarbonate buffer containing HEPES plus $0.1 \%$ BSA (secretion buffer). In the former case, conditioned medium were collected three and 24 hours later. In the later case, after one hour at $37^{\circ} \mathrm{C}$, the buffer was replaced by a secretion buffer containing either no glucose or $50 \mathrm{mM}$ glucose (the latter, in line with glucose concentrations achieved in the GI tract). Three hours later, media were collected, centrifuged at $1,500 \times \mathrm{g}$ and assayed for human insulin using the human-specific insulin ELISA kit (Linco Research, St. Charles, MO, USA), according to manufacturer's instructions. The monoclonal antibody included in the kit recognizes neither preproinsulin nor proinsulin. To standardize the data, total protein were assessed by Bradford method. 


\section{Statistical analysis}

The results were expressed as mean \pm standard error. The student's t-test was used to compare experimental group data. $\mathrm{P}<0.05$ was considered statistically significant.

\section{RESULTS}

The STC-1 cell line is a duodenal tumor-derived cell line (Rindi et al., 1999) containing a heterogeneous and plurihormonal population of cells, including enteroendocrine K-cells and L-cells (Brubacker et al., 2003). To assess gene transfection efficiency and promoter strength in these cells we evaluated the expression of the reporter eGFP gene driven by either the K-cell specific $1.2 \mathrm{~kb}$ GIP promoter (pAAV-GIP/eGFP) or the constitutive CMV promoter (pAAV-CMV/eGFP). Cells transfected with pAAV-CMV/eGFP showed a greater number of eGFP positive cells $(8.7 \%$ vs. $13.6 \%$; $\mathrm{p}<0.05)$ and a 4 -fold higher eGFP fluorescent intensity $(9.1 \pm 0.1$ vs. $35.6 \pm 3.7$; $\mathrm{p}<0.02)$ than cells transfected with pAAV-GIP/eGFP. Thus, as expected, the CMV promoter targets a broader number/type of enteroendocrine cells and results in a stronger expression than when the gene is driven by the GIP promoter.

To determine whether engineered enteroendocrine cells express 1 the preproinsulin gene and process it into mature insulin, STC-1 cells were transfected with plasmids coding for the complete human preproinsulin gene driven either by the K-cell specific GIP promoter (pAAV-GIP/INS) or the CMV promoter (pAAV-CMV/INS). Confocal microscopy analyses of STC-1 cells transfected with pAAV-GIP/INS showed mature human insulin in GIP producing cells (K-cells) (Fig. 1A), but not in GLP-1 producing ones (data not shown). Cells transfected with the pAAV-CMV/INS plasmid showed human mature insulin in both GIP (K-cells) and GLP-1 (L-cells) producing cells (Figs. $1 \mathrm{~B}$ and $1 \mathrm{C}$, respectively). Irrespective of the promoter used, mature human insulin co-localized in a granular pattern with the endogenous hormones, known to be produced and stored in secretory vesicles by enteroendocrine cells (reviewed in Baggio \& Drucker, 2007, Cho and Kieffer, 2010). Consistent with data obtained with the eGFP reporter gene, the frequency of positive cells and the fluorescence intensity for insulin were higher in cells transfected with pAAV-CMV/INS than in cells transfected with pAAV-GIP/ INS (Figs. 1A and 1B).

To determine whether engineered enteroendocrine cells secrete transgenic insulin, STC-1 cells were transfected with plasmids coding for the complete human preproinsulin gene driven either by the K-cell specific GIP promoter (pAAVGIP/INS) or the CMV promoter (pAAV-CMV/INS) and the secretion of human mature insulin levels into the media was assessed. Irrespective of the promoter used, at $25 \mathrm{mM}$ glucose (culture medium concentration) engineered STC-1 cells were able to secrete human insulin (Figs. 2A and B). Further, cells transfected with pAAV-CMV/INS secreted more human insulin than cells transfected with pAAV-GIP/INS (at 24 hours: $5.70 \pm 0.30 \mu \mathrm{U} / \mu \mathrm{g}$ protein vs. $0.57 \pm 0.03 \mu \mathrm{U} / \mu \mathrm{g}$ protein; $\mathrm{P}<$ 0.05) (Fig. 2B).

To determine the glucose dependence of mature human insulin secretion in engineered enteroendocrine cells, STC-1 cells transfected with pAAV-GIP/INS or pAAV-CMV/INS were incubated for 3 hours in Krebs-Ringer buffer containing either no glucose or $50 \mathrm{mM}$ glucose. STC-1 cells transfected with pAAV-GIP/INS showed no significant differences in secreted insulin in the presence or absence of glucose (Fig. 3A). Cells transfected with pAAV-CMV/INS and incubated with $50 \mathrm{mM}$ glucose showed a 3-fold increase $(\mathrm{p}<0.02)$ in secreted insulin into the medium versus cells incubated without glucose (Fig. 3B). Neither detached cells nor morphological changes were observed upon incubation in glucose-free buffer at the different time points.
A

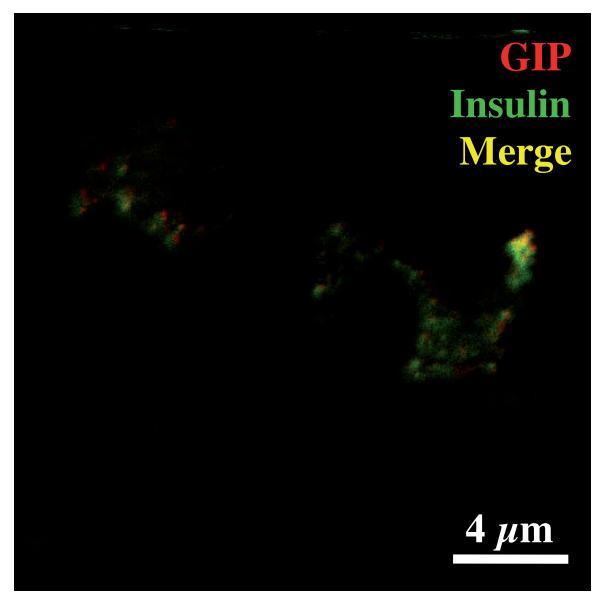

pAAV-GIP/INS
B

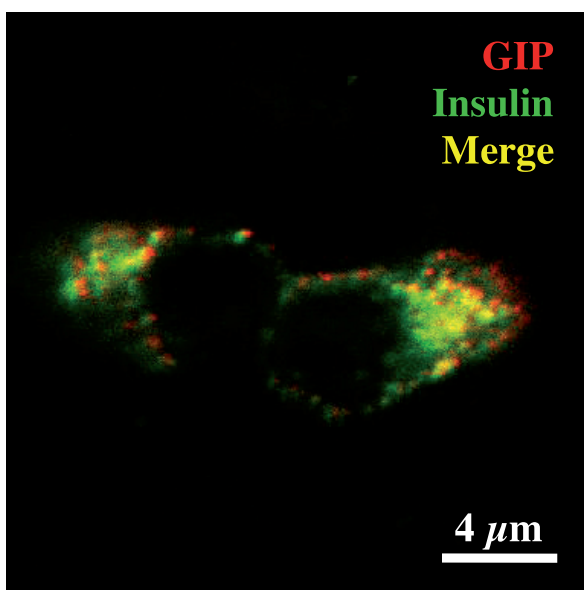

C

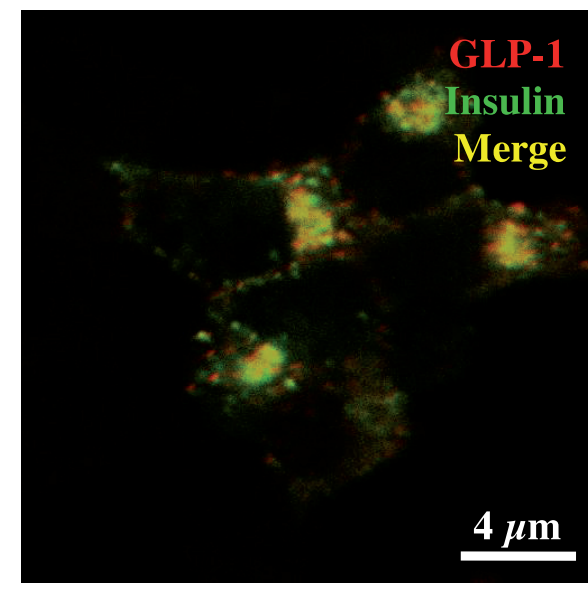

pAAV-CMV/INS

Figure 1. Mature human insulin expression in K-cells and L-cells: STC-1 cells were transfected with (A) pAAV-GIP/INS or (B and C) PAAV-CMV/INS. Immunocytofluorescence with anti-human mature insulin and anti-mouse GIP or anti-mouse GLP-1 was performed. Confocal microphotographs show co-localization of human mature insulin along with endogenous mouse GIP in K-cells (A and B) or with endogenous mouse GLP-1 in L-cells (C). In all cases the granular distribution is characteristic of secretory vesicles. 
A

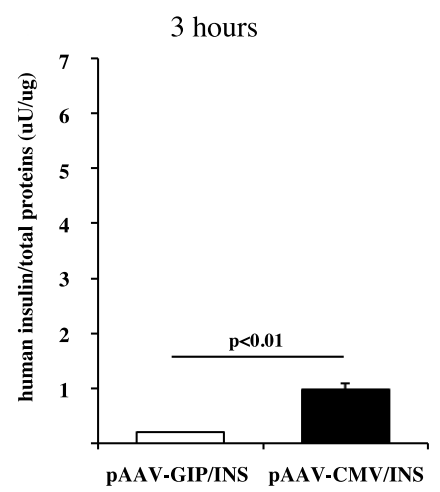

B

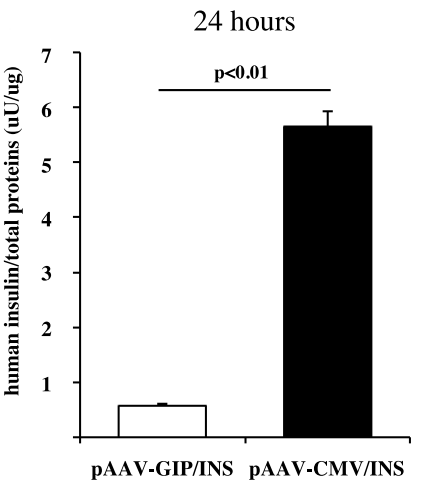

Figure 2. Human mature insulin secretion by gastrointestinal enteroendocrine cells: STC- 1 cells were transfected with $2 \mu \mathrm{g}$ of either PAAV-GIP/INS (open bars) or pAAV-CMV/INS (black bars) plasmids and incubated in DMEM. Following 48 hours, cells were washed twice in PBS and incubated in fresh DMEM containing 25 $\mathrm{mM}$ glucose. Conditioned media were taken at 3 hours $(A)$ and 24 hours (B) and insulin was detected by ELISA by a monoclonal antibody specific for mature human insulin. Under the same experimental conditions, PAAV-CMV/INS transfected cells secreted 5 to 10 times more insulin than cells transfected with PAAV-GIP/ INS. $(n=4)$.

$\mathbf{A}$

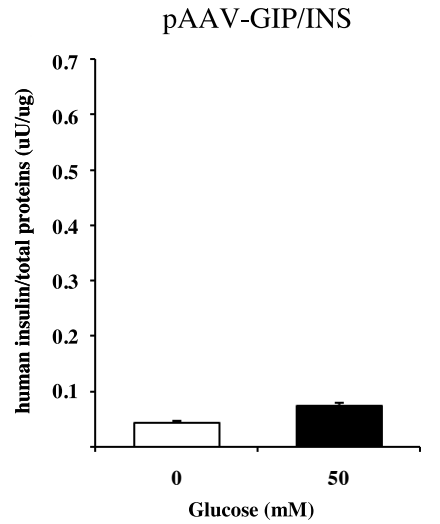

B

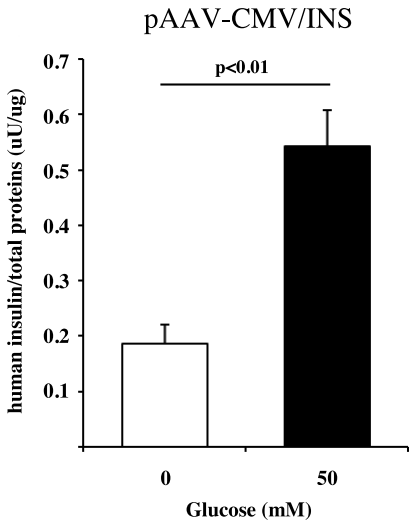

Figure 3. Glucose-dependent mature human insulin secretion by gastrointestinal enteroendocrine cells: STC- 1 cells were transfected with $2 \mu \mathrm{g}$ of either PAAV-GIP/INS (A) or PAAV-CMV/ INS (B) plasmids and incubated in DMEM. After 48 hours, cells were washed twice in PBS and incubated for 3 hours in KrebsRinger buffer without glucose or buffer supplemented with $50 \mathrm{mM}$ glucose. Samples were taken from the supernatant and human insulin was detected by specific human insulin ELISA. PAAV-CMV/ INS transfected cells incubated with glucose showed a 3-fold increase in secreted insulin versus cells incubated without glucose. PAAV-GIP/INS transfected cells incubated with glucose showed only a 1.7-fold increase in secreted insulin versus cells incubated without glucose. $(n=3)$.

\section{DISCUSSION}

Enteroendocrine cells in the small intestine, especially in the duodenum and jejunum, appear as attractive targets for an insulin gene transfer strategy to treat patients with type 1 diabetes mellitus. K-cells and L-cells are innately specialized to respond to nutrients in the lumen, especially glucose, secreting GIP and GLP-1 into the blood, potentiating the glucose-induced insulin response. In normal individuals, the kinetics and plasma concentrations attained for GIP, GLP-1 and insulin following a meal are remarkably similar (Orskov et al., 1996, Fujita et al., 2004) and so are those of GIP and GLP-1 in patients with type 1 diabetes mellitus (Vilsbøll et al., 2003). Furthermore, K-cells and L-cells synthesize the PC1/3 and PC2 peptidases that allow proinsulin processing into mature insulin. Finally, K-cells and L-cells are not destroyed by the immune system of patients with type 1 diabetes mellitus (Vilsbøll et al., 2003).

Previously it has been shown that STC-1 derived K-cells genetically modified with the insulin gene under the control of the GIP promoter secrete insulin in a glucose-dependent manner (Palizban et al., 2007, Han et al., 2007, Li et al., 2008, Zhang et al., 2008). Unfortunately, when transplanted into the peritoneal cavity, diabetic mice developed hypoglycemia (Han et al., 2007, Unniappan et al., 2009). Hypoglycemic states can be potentially fatal and are therefore an unacceptable risk for diabetic patients. This result is most likely explained by an uncontrolled proliferation of these tumor transplanted cells.

Thus far, despite the similarities of pancreatic $\beta$-cells and $\mathrm{K}$-cells and L-cells, the latter have been ignored as a possible target for transgenic insulin expression and secretion. Since an uncontrolled proliferation of tumor cells may compromise the safety of an ex vivo insulin gene transfer strategy to treat a diabetic patient, an in vivo approach to incorporate the insulin gene to normal endogenous intestinal K-cells and L-cells would present mayor advantages. Viral-derived vectors arise as potentially effective transduction methods for insulin gene therapy in the small intestine (Fujita et al., 2004). Here we show that simultaneous transfection of K-cells and L-cells with the human preproinsulin gene driven by CMV promoter results in (i) the synthesis of human mature insulin in both type of cells, (ii) the storage of human mature insulin in GIP-containing vesicles (K-cells) or GLP-1-containing vesicles (L-cells), (iii) the secretion of human mature insulin in a glucose-dependent manner. While the constitutive CMV promoter drives insulin gene expression in both $\mathrm{K}$-cells and L-cells, the GIP promoter excludes L-cells. Moreover, the CMV promoter induces a higher gene expression than the $1.2 \mathrm{~kb}$ GIP promoter. Overall, we have demonstrated that a strong constitutive promoter allows increased insulin synthesis, which is stored in vesicles and secreted after stimulation with glucose in a broader number of target cells, namely L-cells, in addition to K-cells. It is noted that the promoter itself is not responsible for the glucose-regulated hormone secretion, but rather is the chain of cellular events that are normal in enteroendocrine cells.

This proof-of-principle study supports the idea that preproinsulin gene transduction of either L-or K-cells may constitute an adjunct therapy to help manage postprandial hyperglycemia in patients with type 1 diabetes mellitus. 


\section{ACKNOWLEDGEMENTS}

This study was supported the Millennium Scientific Initiative (ICM P05-001F).

\section{REFERENCES}

BAGGIO LL, DRUCKER DJ (2007) Biology of incretins: GLP-1 and GIP. Gastroenterology 132:2131-2157.

BARTLETT RJ, SECORE SL, DENIS M, FERNÁNDEZ L, TZAKIS A, ALEJANDRO R, RICORDI C (1997) Toward the biologic release of human insulin from skeletal muscle. Transplant Proc 29:2199-2200.

BOCHAN MR, SHAH R, SIDNER RA, JINDAL RM (1999) Reversal of diabetes in the rat by injection of hematopoietic stem cells infected with recombinant adeno-associated virus containing the preproinsulin II gene. Transplant Proc 31:690-691.

BRUBAKER PL, IZZO A, ROCCA AS (2003) Synthesis and secretion of intestinal proglucagon-derived peptides by the STC-1 enteroendocrine cell line. Canadian J of Diabetes 27:141-148.

CHEUNG AT, DAYANANDAN B, LEWIS JT, KORBUTT GS, RAJOTTE RV, BRYER-ASH M, BOYLAN MO, WOLFE MM, KIEFFER TJ (2000) Glucose-dependent insulin release from genetically engineered $\mathrm{K}$ cells. Science 290:1959-1962.

CHO YM, KIEFFER TJ (2010) K-cells and glucose-dependent insulinotropic polypeptide in health and disease. Vitam Horm. 84:111-150.

DUPRÉ J, ROSS SA, WATSON D, BROWN JC (1973) Stimulation of insulin secretion by gastric inhibitory polypeptide in man. J Clin Endocrinol Metab 37:826-828.

FALQUI L, MARTINENGHI S, SEVERINI GM, CORBELLA P, TAGLIETTI MV, ARCELLONI C, SARUGERI E, MONTI LD, PARONI R, DOZIO N, POZZA G, BORDIGNON C (1999) Reversal of diabetes in mice by implantation of human fibroblasts genetically engineered to release human mature insulin. Hum Gene Ther 10:1753-1762.

FUJITA Y, CHEUNG AT, KIEFFER TJ (2004) Harnessing the gut to treat diabetes. Pediatric Diabetes 5 Suppl 2:57-69.

GOLDFINE ID, GERMAN MS, TSENG HC, WANG J, BOLAFFI JL, CHEN JW, OLSON DC, ROTHMAN SS (1997) The endocrine secretion of human insulin and growth hormone by exocrine glands of the gastrointestinal tract. Nat Biotechnol 15:1378-1382.

HAN J, LEE HH, KWON H, SHIN S, YOON JW, JUN HS (2007) Engineered enteroendocrine cells secrete insulin in response to glucose and reverse hyperglycemia in diabetic mice. Mol Ther 15:1195-1202.

KOLODKA TM, FINEGOLD M, MOSS L, WOO SL (1995) Gene therapy for diabetes mellitus in rats by hepatic expression of insulin. Proc Natl Acad Sci USA 92:3293-3297.
LI N, YAN-CHENG X, ZHE D, HUI-QIN D (2008) Gene therapy for type 1 diabetes mellitus in rats by gastrointestinal administration of chitosan nanoparticles containing human insulin gene. World J Gastroenterol 14:4209-4215.

LIPES MA, COOPER EM, SKELLY R, RHODES CJ, BOSCHETTI E, WEIR GC, DAVALLI AM (1996) Insulin-secreting non-islet cells are resistant to autoimmune destruction. Proc Natl Acad Sci USA 93:8595-600.

MCINTYRE N, HOLDSWORTH CD, TURNER DS (1964) New interpretation of oral glucose tolerance. Lancet II:20-21.

ORSKOV C, WETTERGREN A, HOLST JJ (1996) Secretion of the incretin hormones glucagon-like peptide- 1 and gastric inhibitory polypeptide correlates with insulin secretion in normal man throughout the day. Scand J Gastroenterol 31:665-670.

MORTENSEN K, CHRISTENSEN LL, HOLST JJ, ORSKOV C (2003) GLP1 and GIP are colocalized in a subset of endocrine cells in the small intestine. Reg. Pept. 114:189-196.

OLSON DE, PAVEGLIO SA, HUEY PU, PORTER MH, THULE PM (2003) Glucose-responsive hepatic insulin gene therapy of spontaneously diabetic BB/Wor rats. Hum Gene Ther 14:1401-1413.

PALIZBAN AA, SALEHI R, NORI N, GALEHDARI H (2007) In vivo transfection of rat small intestine K-cell with pGIP/Ins plasmid by DOTAP liposomes. J Drug Target 15:351-357.

PERLEY M, KIPNIS DM (1970) Plasma insulin responses to oral and intravenous glucose: studies in normal and diabetic subjects. J Clin Invest. 46:1954-1962.

RINDI G, GRANT SG, YIANGOU Y, GHATEI MA, BLOOM SR, BAUTCH VL, SOLCIA E, POLAK JM (1990) Development of neuroendocrine tumors in the gastrointestinal tract of transgenic mice. Heterogeneity of hormone expression. Am J Pathol 136:1349-1363.

SPOONER B S, WALTHER BT, RUTTER WJ (1970) The development of the dorsal and ventral mammalian pancreas in vivo and in vitro. J Cell Biol 47:235-246.

UNNIAPPAN S, WIDEMAN RD, DONALD C, GUNN V, WALL JL, ZHANG Q, WEBBER TD, CHEUNG AT, KIEFFER TJ (2009) Treatment of diabetes by transplantation of drug-inducible insulin-producing gut cells. J Mol Med 87:703-712.

VILSBØLL T, KRARUP T, SONNE J, MADSBAD S, VØLUND A, JUUL AG, HOLST JJ (2003) Incretin secretion in relation to meal size and body weight in healthy subjects and people with type 1 and type 2 diabetes mellitus. J Clin Endocrinol Metab 88:2706-2713.

ZHANG Y, YAO L, SHEN K, XU M, ZHOU P, YANG W, LIU X, QIN X (2008) Genetically engineered $K$ cells provide sufficient insulin to correct hyperglycemia in a nude murine model. Acta Biochim Biophys Sin (Shanghai) 40:149-157. 
